\title{
A method of measuring the Green's function in an enclosure
}

\author{
Luan, Yu; Jacobsen, Finn
}

Published in:

Journal of the Acoustical Society of America

Link to article, DOI:

10.1121/1.2917804

Publication date:

2008

Document Version

Publisher's PDF, also known as Version of record

Link back to DTU Orbit

Citation $(A P A)$ :

Luan, Y., \& Jacobsen, F. (2008). A method of measuring the Green's function in an enclosure. Journal of the Acoustical Society of America, 123(6), 4044-4046. https://doi.org/10.1121/1.2917804

\section{General rights}

Copyright and moral rights for the publications made accessible in the public portal are retained by the authors and/or other copyright owners and it is a condition of accessing publications that users recognise and abide by the legal requirements associated with these rights.

- Users may download and print one copy of any publication from the public portal for the purpose of private study or research.

- You may not further distribute the material or use it for any profit-making activity or commercial gain

- You may freely distribute the URL identifying the publication in the public portal

If you believe that this document breaches copyright please contact us providing details, and we will remove access to the work immediately and investigate your claim. 


\title{
A method of measuring the Green's function in an enclosure (L)
}

\author{
Yu Luan ${ }^{\mathrm{a})}$ and Finn Jacobsen \\ Acoustic Technology, Department of Electrical Engineering, Technical University of Denmark, \\ Building 352, Ørsteds Plads, DK-2800 Kgs. Lyngby, Denmark
}

(Received 10 January 2008; revised 8 April 2008; accepted 8 April 2008)

\begin{abstract}
The acoustic Green's function can be measured using a device with two matched microphones mounted in a tube driven by a loudspeaker combined with another microphone that represents the observation point. Good agreement is obtained between the measured and theoretical Green's function in a rectangular room below $320 \mathrm{~Hz}$. At higher frequencies the agreement is less good because of the imperfect geometry of the room.
\end{abstract}

(C) 2008 Acoustical Society of America. [DOI: 10.1121/1.2917804]

PACS number(s): 43.55.Mc, 43.20.Rz, 43.20.Ks, 43.58.Fm [AJZ] Pages: 4044-4046

\section{INTRODUCTION}

There is a growing need, e.g., in the automotive industry for experimental determination of acoustic transfer functions in connection with analysis of complicated sources. The transfer function of concern, henceforth called the Green's function, is the complex ratio of the sound pressure at a given position to the volume acceleration of a monopole at another position. The purpose of this letter is to examine a simple technique for experimental determination of the Green's function based on pressure microphones mounted in tube driven by a loudspeaker. The technology is commercially available and has been validated in an anechoic room. ${ }^{1}$ In this letter the performance of the device is evaluated in a lightly damped room.

\section{OUTLINE OF THEORY}

The acoustic Green's function is the solution to the inhomogeneous wave equation with a mass injection source term and given boundary conditions, ${ }^{2}$

$$
G\left(\mathbf{r}, \mathbf{r}_{0}\right)=\frac{p(\mathbf{r})}{j \omega \rho Q},
$$

where $p(\mathbf{r})$ is the sound pressure at $\mathbf{r}, Q$ is the volume velocity of a harmonic monopole at $\mathbf{r}_{0}, \omega$ is the radian frequency, and $\rho$ is the density of air. Experimental determination of this quantity obviously involves measuring the frequency response between the volume velocity (or acceleration) of a small source and the signal from a pressure microphone. However, ordinary loudspeakers do not provide a signal proportional to their volume velocity.

Figure 1 shows an arrangement for determining the volume velocity at the opening of the tube, $Q$, driven by a loudspeaker at the other end. The sound pressure signals $p_{A}$ and $p_{B}$ are measured at a distance of $l+\Delta l$ and $l$ from the opening with matched quarter-inch microphones. The tube section has a diameter of $4 \mathrm{~cm}$, from which it follows that the nonaxisymmetric $(1,0)$ and $(2,0)$ modes can propagate above 5.0 and $8.3 \mathrm{kHz}$, respectively. ${ }^{2}$ However, since the mi-

\footnotetext{
a) Author to whom correspondence should be addressed; electronic mail: yl@oersted.dtu.dk.
}

crophones measure the sound pressure on the axis of the tube these modes, which do not contribute to the volume velocity at the opening, are not detected. The cut-on frequency of the first axisymmetric mode is $10.5 \mathrm{kHz}$.

In the frequency range where it can be assumed that only plane waves are measured, the entire sound field can be determined if the sound field is sampled at two positions (unless they are spaced a multiple of half a wavelength), ${ }^{3}$ and the volume velocity at the opening of the tube can easily be shown to be

$$
Q=\frac{S}{\rho c} \cdot \frac{p_{A} \cos k l-p_{B} \cos [k(l+\Delta l)]}{j \sin k \Delta l},
$$

where $S$ is the cross-sectional area of the tube, $c$ is the speed of sound, and $k$ is the wave number. ${ }^{1}$ It now follows that the Green's function is

$$
G\left(\mathbf{r}, \mathbf{r}_{0}\right)=\frac{p_{C}}{j \omega \rho Q}=\frac{Q^{*} p_{C}}{j \omega \rho|Q|^{2}}
$$

[where $\left.p_{C}=p(\mathbf{r})\right]$. Expressed in terms of frequency responses between the three pressure signals the Green's function becomes

$$
\begin{aligned}
G\left(\mathbf{r}, \mathbf{r}_{0}\right)= & \frac{\sin k \Delta l}{k S} \\
& \times \frac{H_{A C} \cos k l-\left|H_{A B}\right|^{2} H_{B C} \cos [k(l+\Delta l)]}{\cos ^{2} k l-2 \operatorname{Re}\left\{H_{A B}\right\} \cos k l \cos [k(l+\Delta l)]+\left|H_{A B}\right|^{2} \cos ^{2}[k(l+\Delta l)]},
\end{aligned}
$$

where the frequency responses $H_{A B}, H_{A C}$, and $H_{B C}$ are estimated in the usual manner from cross and auto spectra, ${ }^{4}$ e.g., the frequency response between microphone signals $A$ and $B$ is the ratio of the cross spectrum $S_{A B}$ to the auto spectrum $S_{A A}$,

$$
H_{A B}=\frac{S_{A B}}{S_{A A}} .
$$

Equation (4) can be simplified if the three signals can be assumed to be perfectly coherent. However, in measurements in enclosures a poor signal-to-noise ratio of the signal from microphone $C$ may occur at antiresonance frequencies. 


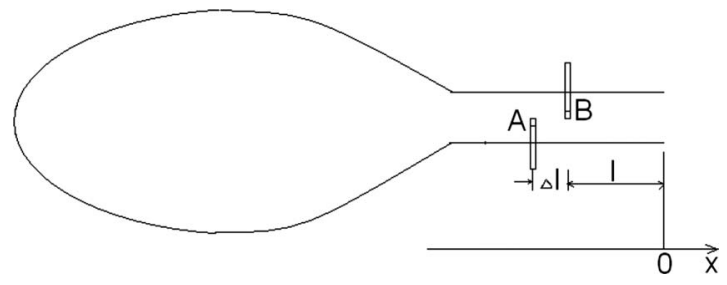

FIG. 1. Device for measuring the output volume velocity.

\section{EXPERIMENTAL RESULTS}

To test the method with a complicated Green's function a simple experiment has been carried out in a lightly damped rectangular room with dimensions $3.29 \times 4.38 \times 3.29 \mathrm{~m}$ and a reverberation time of $5 \mathrm{~s}$ in the frequency range of concern, corresponding to a Schroeder frequency ${ }^{5}$ of $650 \mathrm{~Hz}$. The tube, and thus the room, was driven by a Brüel \& Kjær "OmniSource" (B\&K 4295), a loudspeaker mounted in an "inverted horn" of hard plastic, and radiating through a small opening. ${ }^{6}$ The volume of the inverted horn is about 2.31 . On the source a "Volume velocity adaptor" of type B\&K 4299 was mounted. This device is a 10-cm-long tube of hard plastic that fits the OmniSource and makes it possible to measure the sound pressure at two positions in the tube with a matched set of B\&K 4178 (1/4 in.) microphones (microphones $A$ and $B$ in the foregoing). The dimensions $l$ and $\Delta l$ are 3 and $2 \mathrm{~cm}$, respectively. Finally, the sound pressure at the observation point was measured with a $1 / 2$ in. microphone of type B\&K 4192 (microphone $C$ in the foregoing). The three frequency responses were measured using a $\mathrm{B} \& \mathrm{~K}$ "PULSE" analyzer using a frequency span of $200 \mathrm{~Hz}$, center frequencies between 160 and $600 \mathrm{~Hz}$, and 3200 spectral lines corresponding to a resolution of $62.5 \mathrm{mHz}$. The PULSE analyzer was also used for measuring the reverberation time of the room using the conventional interrupted noise method. No correction for possible phase and amplitude mismatch between the matched microphones was attempted, but the agreement between their responses was ascertained by measuring one time with the microphones interchanged.

In what follows measured Green's functions are compared with the theoretical function for an enclosure ${ }^{2,5}$ :

$$
G\left(\mathbf{r}, \mathbf{r}_{0}\right)=-\frac{1}{V} \sum_{m=0}^{\infty} \frac{\psi_{m}(\mathbf{r}) \psi_{m}\left(\mathbf{r}_{0}\right)}{k^{2}-k_{m}^{2}-j k /\left(\tau_{m} c\right)},
$$

where $V$ is the volume of the room, $\psi_{m}$ is the mode shape (a simple product of three cosines in a rectangular room), $k_{m}$ is the wave number corresponding to the natural frequency of the $m$ th mode, and $\tau_{m}$ is the time constant of the mode. The corresponding reverberation time is 13.8 times larger. $^{5}$

Figure 2 shows a typical example of a measured and predicted Green's function in the frequency range between 60 and $260 \mathrm{~Hz}$ for a source position of $(1.65,2.19,0.01) \mathrm{m}$ and a receiver position of $(1.65,2.19,1.04) \mathrm{m}$. As can be seen the agreement is generally quite good, although deviations occur around $160 \mathrm{~Hz}$. It can also be seen that some peaks are underestimated and some troughs are overestimated; and some peaks and troughs are shifted a little. The underestimation of a few peaks and overestimation of a few

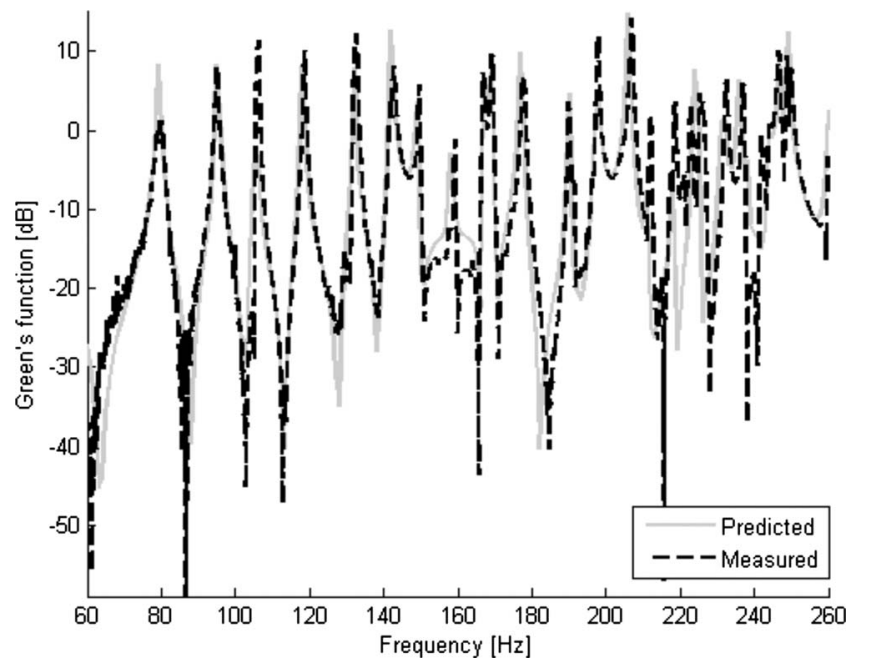

FIG. 2. Measured and predicted Green's function in a rectangular enclosure of $47 \mathrm{~m}^{3}$.

troughs are probably due to the fact that the broadband reverberation time has been measured in the frequency range of concern, whereas the actual modal time constants of different modes may vary. (To determine the individual time constants would require measuring, say, $3 \mathrm{~dB}$ bandwidths of all the modes; and this is only possible when the modes are well separated.) The small frequency shifts that occur, e.g., at $175 \mathrm{~Hz}$ are in all probability due to the fact that the room was not perfectly rectangular.

Figure 3 shows an example of a measured and predicted Green's function in the frequency range between 260 and $460 \mathrm{~Hz}$. The agreement is clearly less good, in particular between 320 and $350 \mathrm{~Hz}$. This is undoubtedly due to the irregular geometry of the room (the floor of the room was, in fact, neither completely horizontal nor completely flat). Above $460 \mathrm{~Hz}$ the agreement (not shown) is in general no longer acceptable, but there is no reason to expect this to be due to a failure of the experimental arrangement.

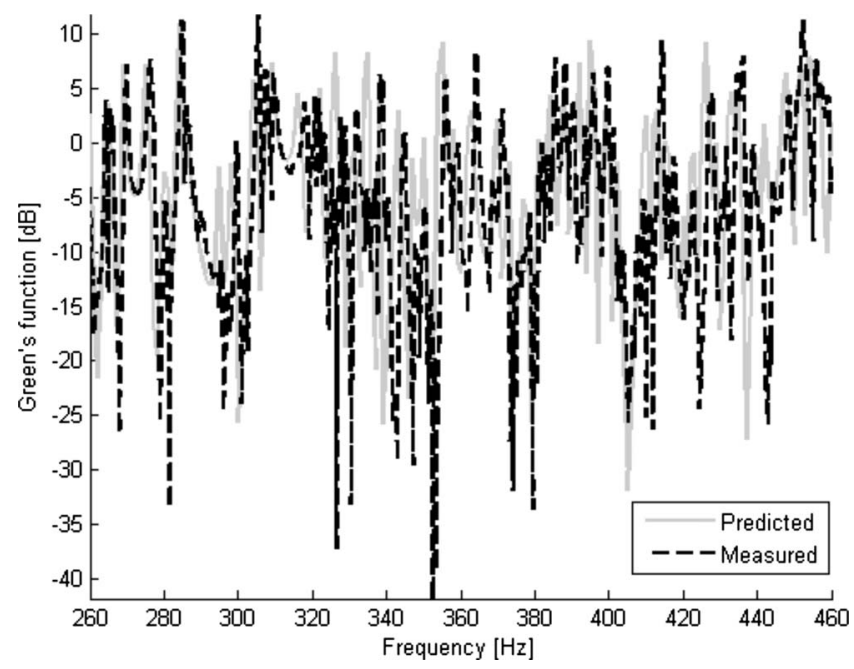

FIG. 3. Measured and predicted Green's function in a rectangular enclosure of $47 \mathrm{~m}^{3}$. 


\section{CONCLUSIONS}

A method of measuring the Green's function has been examined in a rectangular enclosure and found to give results in good agreement with theoretical predictions in the frequency range below $320 \mathrm{~Hz}$. The poor agreement at higher frequencies is due to deviations between the assumed perfectly rectangular geometry and the actual, slightly irregular geometry of the room.

${ }^{1}$ S. Gade, N. Møller, J. Hald, and L. Alkestrup, "The use of volume veloc- ity source in tranfer measurements," in Proceedings of Inter-Noise 2004, Prague, Czech Republic, 2004

${ }^{2}$ P. M. Morse and K. U Ingard, Theoretical Acoustics (McGraw-Hill, New York, 1968).

${ }^{3}$ J. Y. Chung and D. A. Blaser, "Transfer function method of measuring in-duct acoustic properties. I. Theory," J. Acoust. Soc. Am. 68, 907-913 (1980).

${ }^{4}$ J. S. Bendat and A. G. Piersol, Engineering Applications of Correlation and Spectral Processing, 2nd ed. (Wiley, New York, 1993).

${ }^{5}$ H. Kuttruff, Room Acoustics, 4th ed. (E \& FN Spon, London, 2000).

${ }^{6}$ J.-D. Polack, L. S. Christensen, and P. M. Juhl, "An innovative design for omnidirectional sound sources," Acta. Acust. Acust. 87, 505-512 (2001). 